\title{
Purification and Characterization of Crystalline Microbial Alkaline Proteinase Inhibitors (MAPI), Produced by Streptomyces nigrescens WT- $27^{\dagger}$
}

\author{
Takashi Watanabe and Sawao Murao \\ Laboratory of Applied Microbiology, Department of Agricultural Chemistry, \\ University of Osaka Prefecture, Sakai, Osaka 591, Japan
}

Received June 19, 1978

\begin{abstract}
The three microbial alkaline proteinase inhibitors (alpha, beta and gamma-MAPI) have been obtained as needle crystalline forms by a combination of various adsorption and ionexchange column chromatographies.

The crystalline inhibitors showed the same inhibitory spectrum but different inhibitory potential. They strongly inhibited various microbial alkaline proteinases, such as fungal alkaline proteinases, and also inhibited $\alpha$-chymotrypsin, papain, ficin, bromelain and cathepsin $B$.

The three MAPI gave positive Rydon-Smith, Sakaguchi and 2,4-dinitrophenylhydrazine reactions but were negative to ninhydrin reaction. From the amino acid analysis, three MAPI contained arginine, phenylalanine and some aliphatic amino acids; aliphatic amino acid of alpha-MAPI was valine only, that of beta-MAPI was probably valine (small amount of leucine and isoleucine was detected) and that of gamma-MAPI was leucine plus isoleucine (trace amount of valine was also detected).
\end{abstract}

As reported in the previous communications, $\left.{ }^{1,2}\right)$ a novel proteinase inhibitor, having a potent inhibitory action against various microbial alkaline proteinases, was discovered in a culture filtrate of an actinomycete. From the taxonomic studies, the strain was identified as Streptomyces nigrescens. The cultural conditions for the accumulation of the inhibitor were also examined in detail.

The present paper deals with the purification procedure and general properties of the inhibitor from $S$. nigrescens WT-27, together with the inhibitory activity against various proteolytic enzymes.

\section{MATERIALS AND METHODS}

Microorganism and cultural conditions. Streptomyces nigrescens WT-27 was maintained on an agar medium containing $1 \%$ malt extract, $0.4 \%$ yeast extract, $0.4 \%$ glucose and $1.5 \%$ agar, $\mathrm{pH} 7.3$.

The strain was cultured in the best conditions as previously reported.2)

${ }^{\dagger}$ A part of this investigation was presented at the Annual Meeting of the Agricultural Chemical Society of Japan at Nagoya, April, 1978.
Estimation of inhibitor activity. Purification of inhibitor was monitored by measuring inhibitory activity against subtilisin BPN', the assay system of inhibitor and inhibitor unit calculation were the same as described in the previous paper. ${ }^{2)}$

Enzymes and substrates. Subtilisin Carlsberg (crystallized and lyophilized), elastase (hog pancreas, 2 times crystallized), bromelain, proteinase of Aspergillus oryzae and acetone powder of bovine spleen were purchased from Sigma Chemical Co. Human thrombin and human plasmin for medical use were purchased from Green Cross Co., Osaka. Ficin was purchased from Wako Pure Chemical Co., Osaka. Crystalline alkaline proteinase and metallo proteinase of Bacillus subtilis var. amylosacchariticus, carboxyl proteinase of Rhizopus chinensis were a kind gift from Dr. D. Tsuru, Faculty of Pharmaceutical Science, Nagasaki University. Carboxypeptidase $\mathrm{Y}$ was a kind gift from Dr. K. Inouye, Faculty of Agriculture, Kyoto University. Alkaline proteinase of Candida lipolytica ${ }^{3}$ and metallo proteinase of $B$. subtilis YT-254) were kindly supplied by Ajinomoto Co., Kawasaki. Alkaline proteinase of B. subtilis $\mathrm{SO} 4,{ }^{5)}$ alkaline proteinase (I) of Penicillium lilacinum, ${ }^{8)}$ metallo proteinase of Pseudomonas aeruginosa IFO $3455,{ }^{7)}$ carboxyl proteinase of Rhodotorula glutinis, $^{{ }^{8)}}$ carboxyl proteinase of Cladosporium $\mathrm{sp}^{\text {8) }}$ and carboxyl proteinases (A \& B) of Scytalidium lignicolum $^{10)}$ were purified in this laboratory. Other various proteinases employed in the present investigation were 
the same as described previously. ${ }^{2)}$

The substrates, $p$-toluensulfonyl-L-arginine methyl ester (Tos-Arg-OMe), $\mathrm{N}^{\alpha}$-benzoyl-L-arginine ethyl ester (Bz-Arg-OEt), $\mathrm{N}^{\alpha}$-benzoyl-L-argininamide (Bz-Arg$\mathrm{NH}_{2}$ ), $\mathrm{N}^{\alpha}$-benzoyl-L-arginine $p$-nitroanilide $(\mathrm{Bz}-\mathrm{Arg}-$ $\mathrm{NPhNO}_{2}$ ) and $\mathrm{N}^{\alpha}$-benzoyl-L-tyrosine $p$-nitroanilide $\left(\mathrm{Bz}-\mathrm{Ty}-\mathrm{NPhNO} \mathrm{N}_{2}\right.$ ) were purchased from the Foundation for Promotion of Protein Research, Institute for Protein Research, Osaka. Fibrinogen (bovine, plasminogen free) was a product of Pentox. Casein according to Hammarsten was purchased from Wako Pure Chemical Co., Osaka.

\section{Assay system for inhibitory action of MAPI against various proteinases}

1) Microbial alkaline proteinases, microbial metallo proteinases, microbial carboxyl proteinases and elastase (caseinolytic activity). Inhibitory action of MAPI against above proteinases was estimated by the same procedure of subtilisin BPN' assay system described previously, ${ }^{2)}$ excepting the buffer system and enzyme concentration, i.e., in the optimum conditions of each enzyme.

2) a-Chymotrypsin (amidase activity). Mixture containing $0.25 \mathrm{ml}$ of the enzyme solution $(100 \mu \mathrm{g} / \mathrm{ml}$ in $0.05 \mathrm{M}$ phosphate buffer $\mathrm{pH} 7.8$ ) and $0.25 \mathrm{ml}$ of the same buffer with or without inhibitor was preincubated for $10 \mathrm{~min}$ at $37^{\circ} \mathrm{C}$ before addition of $2.5 \mathrm{ml}$ of $0.0006 \mathrm{M}$

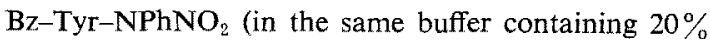
$(\mathrm{v} / \mathrm{v})$ dimethylformamide). After a further $15 \mathrm{~min}$ incubation at $37^{\circ} \mathrm{C}$, the reaction was terminated by addition of $0.5 \mathrm{ml}$ of $30 \%$ acetic acid and read the absorbance at $410 \mathrm{~nm}$.

3) Thrombin and plasmin (esterolytic activity). Esterolytic activity of thrombin and plasmin toward Tos-Arg-OMe was determined by the same method of kallikrein, described previously. ${ }^{2)}$

4) Plasmin (fibrinolytic activity). Fibrin clot lysis activity of plasmin was measured by the method described previously. I.1)

5) Thrombin (fibrinogen cloting activity). Human thrombin activity was measured by bovine fibrinogen clotting activity according to the method of Magnusson. ${ }^{12)}$

6) Bromelain and ficin (caseinolytic activity). Caseinolytic activity of bromelain and ficin was estimated by the same method of papain, as described previously. ${ }^{2}$ )

7) Cathepsin B. Acetone powder $(50 \mathrm{mg})$ of bovine spleen was extracted with $5 \mathrm{ml}$ of $0.05 \mathrm{M}$ phosphate buffer ( $\mathrm{pH} \mathrm{6.0)}$ and insoluble material was removed by centrifugation ( $8000 \mathrm{rpm}$ for $10 \mathrm{~min}$ ), the resulting supernatant was used as cathepsin $\mathrm{B}$ assay. Mixture consisting of $0.2 \mathrm{ml}$ enzyme solution, $0.1 \mathrm{ml}$ of activator solution $(0.05 \mathrm{M}$ cysteine- $\mathrm{HCl}$ and $0.02 \mathrm{M}$ ethylenediamine tetraacetic acid, $\mathrm{pH} 6.0$ ) and $0.2 \mathrm{ml}$ of the same buffer with or without inhibitor was preincubated for $5 \mathrm{~min}$ at $37^{\circ} \mathrm{C}$ before addition of $0.25 \mathrm{ml}$ of $0.001 \mathrm{M} \mathrm{Bz}-\mathrm{Arg}-\mathrm{NPhNO}_{2}$ solution (in the same buffer containing $1 \%$ dimethyl sulfoxide) and incubated for $6 \mathrm{hr}$ at $37^{\circ} \mathrm{C}$. The reaction was terminated by addition of $1 \mathrm{ml}$ of $30 \%$ acetic acid and read the absorbance at $410 \mathrm{~nm}$.

8) Carboxypeptidase $Y$. Amidase activity of carboxypeptidase $\mathrm{Y}$ toward $\mathrm{Bz}-\mathrm{Tyr}-\mathrm{NPhNO}_{2}$ was determined by the method described by Aibara et al. ${ }^{13)}$

Miscellaneous analytical methods. Ultraviolet ab. sorption spectrum of inhibitor was measured with a recording spectrophotometer (Hitachi 200-10). Highspeed liquid chromatograph employed in preparative and analytical works was Hitachi 635 liquid chromatograph. Amino acids were analyzed with an amino acid analyzer (Hitachi KLA-5).

Peptides in the eluates of column chromatography were measured by ninhydrin after alkaline hydrolysis method. ${ }^{14)}$

Resin. Amberlite XAD-2 (20 50 mesh), XAD-7 $(20 \sim 50$ mesh $), \quad$ CG-50 $(200 \sim 400$ mesh $)$ and IR-45 were purchased from Organo Co., Tokyo. Dowex $1 \times 2(50 \sim 100$ mesh) from Muromachi Kagaku, Osaka. Aluminium oxide and silica gel from Merck Japan.

\section{RESULTS}

\section{Purification of $M A P I$}

Step 1. Purification source. After cultivation, as described in MATERIALS AND MeTHODS, the cultured broth was centrifuged ( $8000 \mathrm{rpm}$ for $15 \mathrm{~min}$ ) to remove mycelium and the supernatant ( 7.45 liters) was used as purification source.

Step 2. Amberlite XAD-2 column chromatography. The active culture supernatant obtained in Step 1 was applied to an Amberlite XAD-2 column $(5 \times 20 \mathrm{~cm})$ equilibrated with deionized water. After washing the column with about 5 liters of deionized water, the adsorbed inhibitor was eluted with $80 \%$ methanol solution at a flow rate of $100 \mathrm{ml} / \mathrm{hr}$, the adsorbed inhibitor emerged from the colu$\mathrm{mn}$ immediately after changing of solvent. The active fractions $(1420 \mathrm{ml})$ were evaporated to syrup in vacuo at $40^{\circ} \mathrm{C}$ by a rotary evaporator. 
Step 3. n-Butanol extraction. The resulting syrup (about $300 \mathrm{ml}$ ) was extracted with $500 \mathrm{ml}$ of $n$-butanol, and then the $n$-butanol layer was washed with an equal volume of water twice and concentrated to syrup in vacuo.

Step 4. Amberlite XAD-7 column chromatography. The active material obtained in Step 3 was dissolved in $74 \mathrm{ml}$ of $50 \%$ methanol, and the solution was applied to an Amberlite XAD-7 column $(3.5 \times 20 \mathrm{~cm})$ equilibrated with $50 \%$ methanol. After the column was washed with 1.2 liters of $50 \%$ methanol and 1 liter of $80 \%$ methanol, inhibitor was eluted with $80 \%$ methanol containing $0.05 \mathrm{~N} \mathrm{HCl}$. Fractions having inhibitory activity were pooled. The bulked eluate $(450 \mathrm{ml})$ was neutralized by passing an Amberlite IR-45 column $(5 \times 3.2 \mathrm{~cm})$, and then evaporated dryness in vacuo.

Step 5. Dowex $1 X 2$ column chromatography. The dry active material was dissolved in $100 \mathrm{ml}$ of $80 \%$ methanol, and then applied to a column of Dowex 1X2 (acetate form) $(5 \times 6.4 \mathrm{~cm})$ equilibrated with $80 \%$ methanol. Inhibitor was eluted with the same solvent, a large amount of colored impurities was removed by this step.

Step 6. Amberlite CG-50 column chromatography. The bulked eluate $(300 \mathrm{ml})$ from Dowex 1X2 column was evaporated to dryness in vacuo, and then active material was dissolved in $120 \mathrm{ml}$ of $0.1 \mathrm{M}$ pyridine-acetic acid buffer (pH 4.8)-30\% methanol solution. The active solution was applied to an Amberlite CG-50 column $(3.5 \times 16 \mathrm{~cm})$ equilibrated with $0.1 \mathrm{M}$ pyridine-acetic acid buffer ( $\mathrm{pH} \mathrm{4.8)-30 \%}$ methanol and developed with the same buffered solvent. Inhibitor was eluted with $0.1 \mathrm{M}$ acetic acid- $80 \%$ methanol. The active fractions were pooled.

Step 7. Aluminium oxide column chromatography. The pooled eluate $(620 \mathrm{ml})$ from Step 6 was evaporated to dryness in vacuo, the dry active material was suspended in $50 \mathrm{ml}$ of $n$-butanol: $\mathrm{H}_{2} \mathrm{O}(19: 1)$ and applied to an aluminium oxide column $(5 \times 9 \mathrm{~cm})$ equilibrated with $n$-butanol: $\mathrm{H}_{2} \mathrm{O} \quad(19: 1)$. After developing the column with the same solvent mixture and $n$-butanol: $\mathrm{H}_{2} \mathrm{O}(9: 1)$, the inhibitor was eluted with a linear gradient from $n$-butanol: $\mathbf{H}_{2} \mathrm{O}(9: 1)$ to $n$-butanol: methanol: $\mathrm{H}_{2} \mathrm{O}(8: 1: 1)$. The active fractions were collected.

Step 8. Silica gel column chromatography. The pooled eluate $(920 \mathrm{ml})$ from Step 7 was evaporated to dryness in vacuo. The dry active material was dissolved and/or suspended in $40 \mathrm{ml}$ of ethylacetate: $n$-butanol: acetic acid (5:5:1) and applied to a silica gel column $(2 \times 38 \mathrm{~cm})$, previously equilibrated with the same solvent mixture. The inhibitor was eluted with a linear gradient from the starting solvent mixture to $n$-butanol: $\mathrm{H}_{2} \mathrm{O}(9: 1)$. The active fractions were collected.

Step 9. Preparative high-speed liquid chromatography. The pooled eluate $(850 \mathrm{ml})$ from Step 8 was evaporated to dryness in vacuo. Drying the material in a vacuum desicator gave an active white amorphous powder (292 mg).

This preparation had the same homogeneity as the sample described in the previous communication, ") when examined by a thin-layer chromatography. However, detailed investigations on the conditions of analytical highspeed liquid chromatography revealed an apparent chromatographic heterogeneity of this preparation. Accordingly the present investigation was made to separate each component in this preparation by a preparative high-speed liquid chromatography.

Ten $\mathrm{mg}$ of the preparation obtained in Step 8 was dissolved in $10 \mathrm{ml}$ of $50 \%$ methanol, insoluble material was removed by filtration and applied to a chromatograph. A typical elution profile is shown in Fig. 1. A good separation into three fractions, followed after first emerging of solvent or some impurities was achieved. In order of their retention time, each fraction was designated as alpha-MAPI (fractions having retention time from $48 \mathrm{~min}$ to $65 \mathrm{~min})$, beta-MAPI $(84 \mathrm{~min} \sim 112 \mathrm{~min})$, gamma-MAPI (148 $\min \sim 200 \mathrm{~min})$, respectively. In this chromatographic conditions, gamma-MAPI fractions were seemingly inactive 


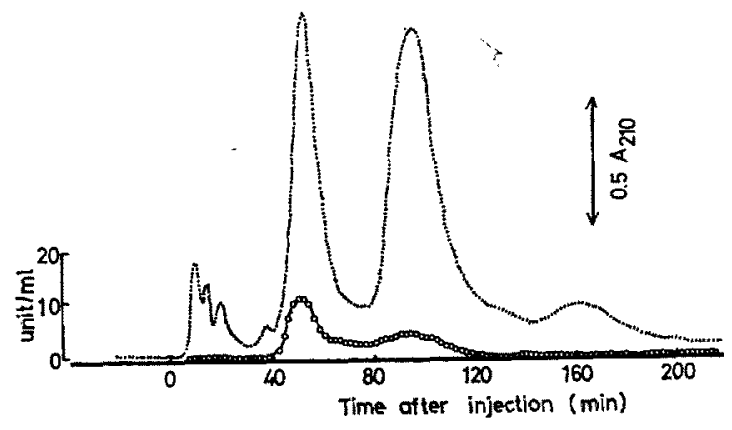

FIG. 1. Preparative High-speed Liquid Chromatogram of MAPI.

Ten $\mathrm{mg}$ of sample was dissolved in $10 \mathrm{ml}$ of $50 \%$ methanol and applied to an apparatus. Chromatographic conditions are as follows: packing material, Hitachi gel $\$ 3019$; column size, $8 \times 500 \mathrm{~mm}$ dual; column temperature, $50^{\circ} \mathrm{C}$; eluent, $50 \%$ methanol; flow rate, $3.0 \mathrm{ml}$ per $\mathrm{min}$; pressure, $10 \mathrm{~kg}$ per $\mathrm{cm}^{2}$; detector, UV monitoring at $210 \mathrm{~nm}$. Eluate from the column was fractionated at each $2 \mathrm{~min}$ intervals. $\mathrm{O}-\mathrm{O}$, inhibitory activity against subtilisin $\mathrm{BPN}^{\prime}$; -----, absorbance recording at $210 \mathrm{~nm}$.

but showed a weak inhibitory activity in higher concentration.

Twenty five time's run in the same conditions were carried out and obtained three fractions. Evaporating the pooled eluate gave a white amorphous powder (alpha-MAPI, $39.4 \mathrm{mg}$;
beta-MAPI, $103.4 \mathrm{mg}$; gamma-MAPI, 24.1mg).

Step 10. Crystallization. The white powder of Step 9 was dissolved in a minimum volume of $80 \%$ methanol. Needle crystals of each MAPI appeared after standing the solution at room temperature for a few days. Crystals were collected by filtration on a glass filter, and washed with small volume of acetone. After drying in a vacuum desicator for overnight, $27.8 \mathrm{mg}$ of alpha-MAPI, $60.2 \mathrm{mg}$ of beta-MAPI and $8.2 \mathrm{mg}$ of gamma-MAPI were obtained.

A summary of the purification of MAPI from the culture medium of Streptomyces nigrescens WT-27 is shown in Table I.

\section{Homogeneity of MAPI}

The crystals of three MAPI gave a single spot on a thin-layer chromatography, while three MAPI represented same $R f$ value. On a thin-layer chromatography using Silica gel 60 (E. Merck); Rf 0.17 in $n$-butanol: $\mathrm{H}_{2} \mathrm{O}(9: 1)$, Rf 0.40 in $n$-butanol: methanol: $\mathrm{H}_{2} \mathrm{O}(4: 1: 2)$, Rf 0.63 in $n$-propanol: methanol: $\mathrm{H}_{2} \mathrm{O}(5: 1: 2)$.

On a paper electrophoresis using a buffer consisting of $80 \%$ formic acid: acetic acid: $\mathrm{H}_{2} \mathrm{O}(50: 15: 800) \mathrm{pH} 1.9(10 \mathrm{v} / \mathrm{cm}$ for $2 \mathrm{hr}$

Table I. Summary of Purification Procedure of MAPI

\begin{tabular}{lrrrrr}
\cline { 3 - 5 } Step & Vol. (ml) & $\begin{array}{c}\text { Total } \\
\text { peptide }^{a}\end{array}$ & $\begin{array}{c}\text { Total } \\
\text { activity }^{b}\end{array}$ & $\begin{array}{c}\text { Specific } \\
\text { activity }^{c}\end{array}$ & $\begin{array}{c}\text { Recovery } \\
(\%)\end{array}$ \\
\hline Culture medium & 7,450 & 912,000 & 52,500 & 0.058 & 100 \\
Amberlite XAD-2 & 1,420 & 27,000 & 79,000 & 2.9 & 151 \\
$n$-Butanol extraction & 420 & 8,900 & 50,700 & 5.7 & 97 \\
Amberlite XAD-7 & 450 & 1,520 & 43,900 & 28.9 & 84 \\
Dowex 1X2 & 300 & 1,380 & 40,000 & 29.0 & 76 \\
Amberlite CG-50 & 650 & 1,090 & 32,700 & 30.0 & 62 \\
Aluminium oxide & 920 & 937 & 31,500 & 33.6 & 60 \\
Silica gel & 850 & 561 & 19,700 & 35.1 & 38 \\
Preparative HSLC ${ }^{d}$ & & & & & \\
$\quad \alpha$-MAPI & 1,260 & 231 & 10,100 & 43.7 & 19 \\
$\quad \beta$-MAPI & 2,140 & 401 & 4,840 & 12.1 & 9 \\
$\quad \gamma$-MAPI & 3,900 & 118 & 656 & 5.6 & 1 \\
Crystallization & & & & & \\
$\quad \alpha$-MAPI & - & 99 & 5,590 & 56.5 & 11 \\
$\beta$-MAPI & - & 166 & 2,050 & 12.3 & 4 \\
$\quad \gamma$-MAPI & - & 25 & 176 & 7.0 & 0.3 \\
\hline
\end{tabular}

a Absorbance at $570 \mathrm{~nm}$ of ninhydrin after alkaline hydrolysis.

$b$ Inhibitor activity against subtilisin BPN'.

- Total activity/total peptide. d High-speed liquid chromatography. 


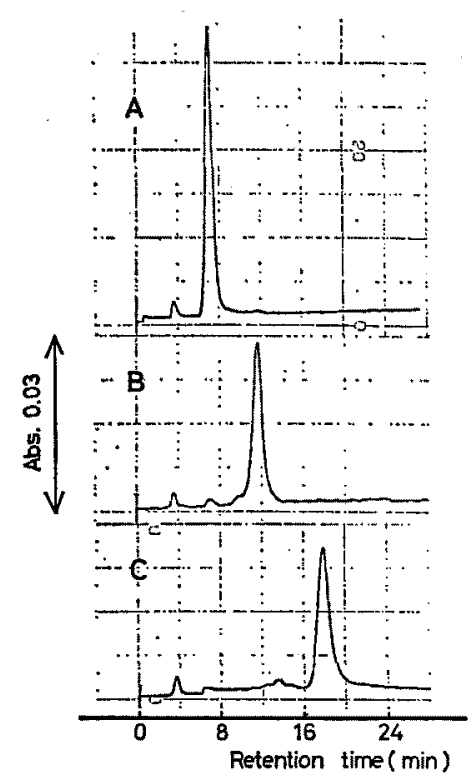

FIG. 2. Analytical High-speed Liquid Chromatogram of MAPI.

Five $\mu$ l of each MAPI solution (ca. $0.1 \%$ concentration in $80 \%$ methanol) was applied to an apparatus. The chromatographic conditions are as follows; packing material, LiChrosorb RP-18 $(5 \mu \mathrm{m})$; column size, $4 \times 150 \mathrm{~mm}$; column temperature, ambient; eluent, $0.02 \mathrm{M}$ phosphate buffer $\mathrm{pH} 7.0$ containing $60 \%$ methanol; flow rate, $0.5 \mathrm{ml}$ per min; pressure, $100 \mathrm{~kg}$ per $\mathrm{cm}^{2}$; detector, UV monitoring at $210 \mathrm{~nm}$; absorbance unit full scale, 0.16 .

A, alpha-MAPI; B, beta-MAPI; C, gamma-MAPI.

on a Toyo filter paper No. 51), three MAPI moved toward cathode with same $R m$ value of 0.74 (relative movement to glycine).

However, three MAPI had different retention times on an analytical high-speed liquid chromatography, as shown in Fig. 2.

\section{General properties of $M A P I$}

Ultraviolet absorption spectrum. The ultraviolet absorption spectrum of three MAPI in $80 \%$ methanol solution showed maximum at $268 \mathrm{~nm}, 264 \mathrm{~nm}, 258 \mathrm{~nm}, 252 \mathrm{~nm}$ and $247 \mathrm{~nm}$ with a shoulder at $260 \mathrm{~nm}$, the spectrum could be superimposed to the absorption spectrum of phenylalanine, representing that three MAPI have phenylalanine residue in the molecule. A $1.0 \%$ solution of alpha-MAPI in $80 \%$ methanol solution had an absorbance of 5.1 at $268 \mathrm{~nm}, 6.75$ at $264 \mathrm{~nm}, 8.55$ at $258 \mathrm{~nm}$,
7.4 at $252 \mathrm{~nm}$ and 6.05 at $247 \mathrm{~nm}$. Similar results were observed in the case of beta-MAPI and gamma-MAPI.

Chemical analysis. Three MAPI gave positive Rydon-Smith, chlorine-tolidine, sodium nitroprusside-ferricyanide, phenanthrenequinone, Sakaguchi, $\alpha$-naphtol-diacetyl, Tollens, 2,4-dinitrophenylhydrazine, 2,3,5-triphenyltetrazolium chloride reactions but negative Pauly, Ehrlich, Folin-Ciocalteu and ninhydrin reactions. These results suggested that three MAPI were a type of peptides, containing arginine and some reducing group.

Table II. Amino Acid Composition of MAPI

\begin{tabular}{lccc}
\hline \multicolumn{1}{c}{ Amino acid } & \multicolumn{3}{c}{ Molar ratio $^{a}$} \\
& $\alpha$-MAPI & $\beta$-MAPI & $\gamma$-MAPI \\
\hline Phenylalanine & 1.00 & 1.00 & 1.00 \\
Valine & 9.92 & 9.16 & 0.24 \\
Leucine & 0.00 & 0.37 & 2.25 \\
Isoleucine & 0.00 & 0.60 & 5.51 \\
Arginine & 0.89 & 0.92 & 1.04 \\
\hline
\end{tabular}

a Relative molar ratio compared to phenylalanine.

After acid hydrolysis of three MAPI in evacuated tube $\left(6 \mathrm{~N} \mathrm{HCl}, 110^{\circ} \mathrm{C}\right.$ for $\left.44 \mathrm{hr}\right)$, amino acid constituents were analyzed with amino acid analyzer, the results are shown in Table II. Three MAPI contained phenylalanine, arginine and some aliphatic amino acids.

\section{Inhibitory spectrum of $M A P I$}

As reported in the previous papers, ${ }^{1,2}$ mixtures of three MAPI had inhibitory actions against various microbial alkaline proteinases, $\alpha$-chymotrypsin and papain. The present paper investigated the inhibitory effect of three MAPI against various proteinases including serine, metallo, thiol and carboxyl proteinases, the results are summarized in Table III. Three MAPI had the same inhibitory specificities, they inhibited microbial alkaline proteinases of various origins, $\alpha$-chymotrypsin and thiol proteinases (papain, ficin, bromelain and cathepsin B) but not trypsin, plasmin, kallikrein, thrombin, elastase, metallo proteinases and carboxyl proteinases. However, three MAPI had different inhibitory potential. These 
Table III. Inhibitory Sectrum of MAPI on Various Proteinases

Inhibitory action of MAPI was estimated by measuring residual enzyme activity after incubation of each enzyme with inhibitor $(50 \mu \mathrm{g})$.

Inhibitory ratings used are as follows: + , more than $80 \%$ inhibition; - , less than $10 \%$ inhibition of enzyme activity.

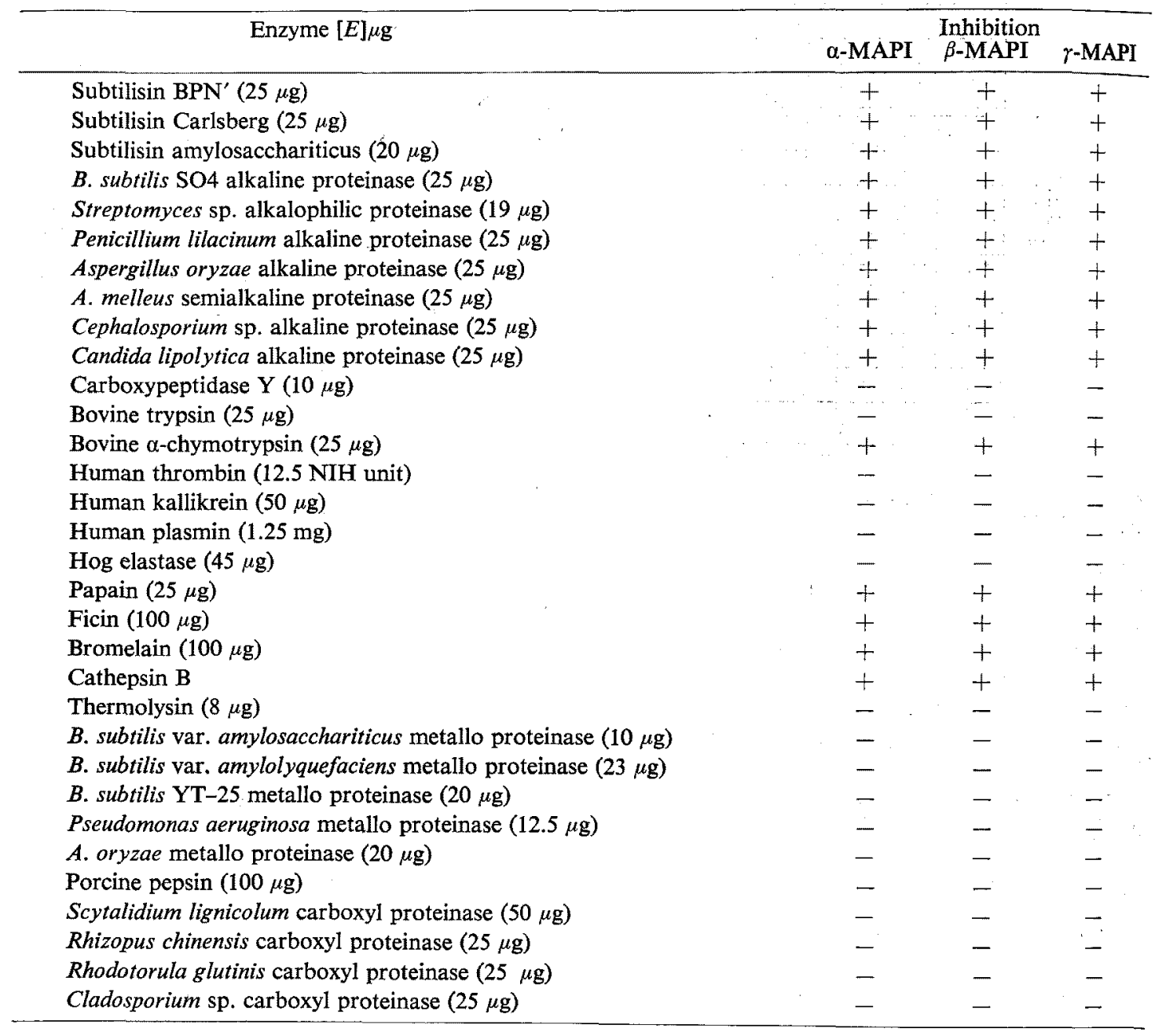

Table IV. Inhibition of Serine and Thiol Proteinase by MAPI

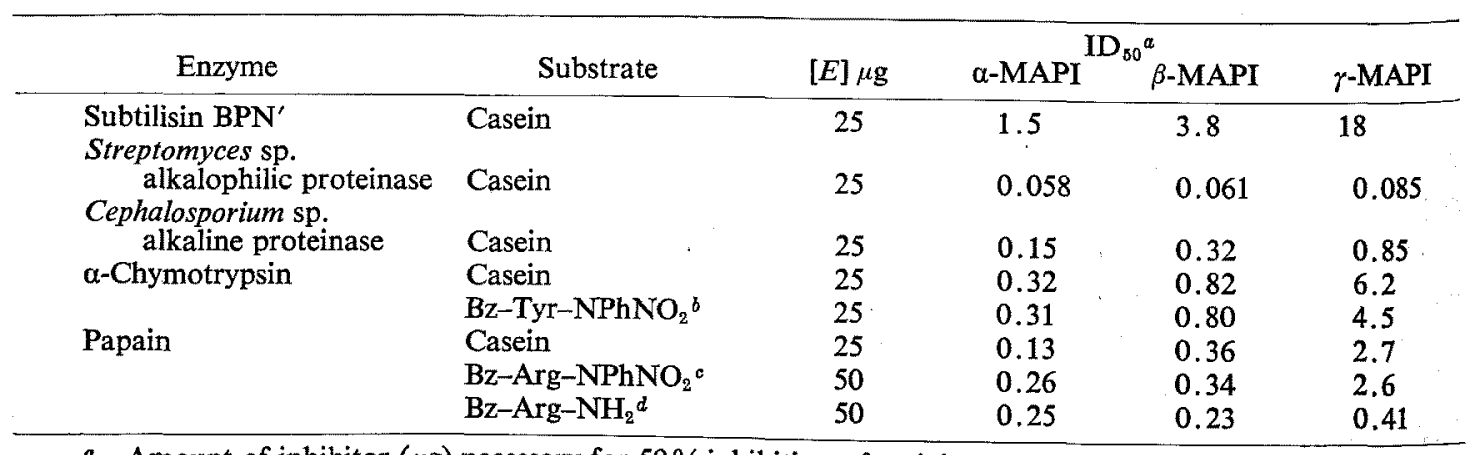

a Amount of inhibitor $(\mu \mathrm{g})$ necessary for $50 \%$ inhibition of activity.

$b \quad \mathrm{~N}^{\alpha}$-Benzoyl-L-tyrosine $p$-nitroanilide.

- $\mathbf{N}^{\alpha}$-Benzoyl-L-arginine $p$-nitroanilide.

d $\mathrm{N}^{\alpha}$-Benzoyl-L-argininamide. 
enzymes were preincubated with different amount of MAPI and the changes in residual enzyme activities were measured using appropriate substrates. The results are shown in Table IV, indicating that alpha-MAPI had more potent inhibitory actions than the other two. In addition, it is noteworthy that inhibition against alkaline proteinases of actinomycetes, fungal or yeast origin was more potent than that of bacterial origin.

\section{DISCUSSION}

Peptidic inhibitors, MAPI, were finally purified by a preparative high-speed liquid chromatography into three components (alpha, beta and gamma-MAPI) as needle crystals from the culture filtrate of Streptomyces nigrescens WT-27.

Three MAPI had the same inhibitory spectrum but different inhibitory potential. MAPI strongly inhibited caseinolytic activity of various microbial alkaline proteinases, such as fungal alkaline proteinases. In addition, $\alpha$ chymotrypsin and thiol proteinases (papain, ficin, bromelain and cathepsin B) were also inhibited by three MAPI.

The three MAPI gave positive Rydon-Smith, Sakaguchi and 2,4-dinitrophenylhydrazine reactions but were negative to ninhydrin reaction. From the amino acid analysis, three MAPI contained arginine, phenylalanine and some aliphatic amino acid; aliphatic amino acid of alpha-MAPI is valine only, that of betaMAPI is probably valine (small amount of leucine and isoleucine was detected) and that of gamma-MAPI is leucine plus isoleucine (trace amount of valine was also detected).

Recently, several proteinases inhibitors of peptide aldehyde type, having the C-terminal aldehyde structure, have been discovered and reviewed by $\mathrm{H}$. Umezawa et $a l_{.}{ }^{15,16)}$ As discussed in the previous communication, ${ }^{2}$ MAPI had similar inhibitory specificities to chymotrypsin inhibitor "chymostatin," having inhibitory actions against $\alpha$-chymotrypsin and papain. ${ }^{17)}$ As reported by $\mathrm{H}$. Umezawa, ${ }^{17}$, chymostatin weakly inhibits papain-hydrolysis of casein but not papain-hydrolysis of $\mathrm{Bz}-$ Arg- $-\mathrm{NH}_{2}$. The three MAPI apparently differ from chymostatin, as they inhibited not only caseinolytic activity of papain but also amidase activity of papain, their inhibitory rate against papain was of similar order to that of antipain $^{18}$ or leupeptin. ${ }^{19}$ It is noteworthy that basic amino acid residue of chymostatin is a diastereomer of capreomycidine, ${ }^{201}$ but that of the three MAPI is arginine.

The detailed descriptions on the structural elucidation of MAPI will be presented elsewhere.

\section{REFERENCES}

1) S. Murao and T. Watanabe, Agric. Biol. Chem., 41, 1313 (1977).

2) S. Murao and T. Watanabe, ibid., 42, 2209 (1978).

3) S. Tobe, T. Takami, S. Ikeda and K. Mitsugi, ibid., 40, 1097 (1976).

4) S. Murao and Y. Takahara, ibid., 38, 2305 (1974).

5) S. Murao, K. Oda and S. Omata, Abstracts of Papers, Annual Meetings of Agricultural Chemical Society of Japan, Tokyo, 1969, p. 59.

6) M. Arai and S. Murao, Agric. Biol. Chem., 41, 2293 (1977).

7) K. Morihara, H. Tsuzuki, T. Oka, H. Inoue and M. Ebata, J. Biol. Chem., 240, 3295 (1965).

8) M. Kamada, K. Oda and S. Murao, Agric. Biol. Chem., 36, 1095 (1972).

9) S. Murao, S. Funakoshi and K. Oda, ibid., 36, 1327 (1972).

10) S. Murao, K. Oda and T. Matsushita, ibid., 36, 1647 (1972).

11) S. Sato and S. Murao, ibid., 37, 1067 (1973).

12) S. Magnusson, "Methods in Enzymology," Vol. XIX, ed. by E. Perlman and L. Lorand, Academic Press Inc., New York, N. Y., 1970, p. 157.

13) S. Aibara, R. Hayashi and T. Hata, Agric. Biol. Chem., 35, 658 (1971).

14) C. H. W. Hirs, S. Moore and W. H. Stein, J. Biol. Chem., 219, 623 (1956).

15) H. Umezawa, "Methods in Enzymology," Vol. XLV, ed. by L. Lorand, Academic Press Inc., New York, N. Y., 1976, p. 678.

16) H. Umezawa and T. Aoyagi, "Proteinases in mammalian cells and tissues," ed. by A. J. Barrett, North-Holland Publishing Co., Amsterdam., 1977, p. 637.

17) H. Umezawa, T. Aoyagi, H. Morishima, S. Kunimoto, M. Matsuzaki, M. Hamada and T. Takeuchi, J. Antibiot., 23, 425 (1970).

18) H. Suda, T. Aoyagi, M. Hamada, T. Takeuchi 
and H. Umezawa, J. Antibiot., 25, 263 (1972).

19) T. Aoyagi, T. Takeuchi, A. Matsuzaki, K. Kawamura, S. Kondo, M. Hamada, K. Maeda and
H. Umezawa, J.' Antibiot., 22, 283 (1969).

20) K. Tatsuta, N. Mikami, K. Fujimoto, S. Umezawa and T. Aoyagi, ibid., 26, 625 (1973). 